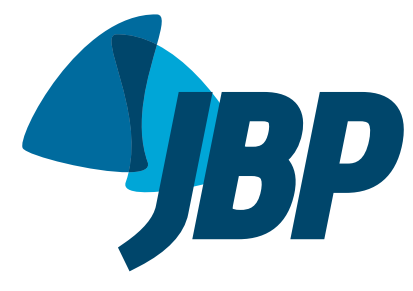

\title{
Comparison of diaphragmatic mobility between COPD patients with and without thoracic hyperkyphosis: a cross-sectional study
}

\author{
Márcia Aparecida Gonçalves ${ }^{1, a}$, Bruna Estima Leal ${ }^{1, b}$, \\ Liseane Gonçalves Lisboa ${ }^{2, c}$, Michelle Gonçalves de Souza Tavares ${ }^{3, \mathrm{~d}}$, \\ Wellington Pereira Yamaguti ${ }^{4, e}$, Elaine Paulin ${ }^{1, f}$
}

1. Departamento de Fisioterapia e Programa de Pós-Graduação em Fisioterapia, Universidade do Estado de Santa Catarina - UDESC -

Florianópolis (SC) Brasil.

2. Departamento de Radiologia, Clínica Lâmina Medicina Diagnóstica, Florianópolis (SC) Brasil.

3. Programa de Pós-Graduação em Ciências Médicas - PPGCM Universidade Federal de Santa Catarina - UFSC - Florianópolis (SC) Brasil.

4. Departamento de Reabilitação, Hospital Sírio-Libanês, São Paulo (SP) Brasil.

a. (D) http://orcid.org/0000-0002-6518-6227

b. (iD) http://orcid.org/0000-0001-6064-4199

c. (iD http://orcid.org/0000-0001-8834-3339

d. (iD http://orcid.org/0000-0002-5390-8739

e. (iD) http://orcid.org/0000-0003-4943-2085

f. (D) http://orcid.org/0000-0001-7306-2817

Submitted: 5 November 2016.

Accepted: 15 October 2017.

Study carried out in the Laboratório de Fisioterapia Respiratória - LAFIR -

Universidade do Estado de Santa Catarina - UDESC - Florianópolis (SC) Brasil.

\begin{abstract}
Objective: To compare diaphragmatic mobility, lung function, and respiratory muscle strength between COPD patients with and without thoracic hyperkyphosis; to determine the relationship of thoracic kyphosis angle with diaphragmatic mobility, lung function, and respiratory muscle strength in COPD patients; and to compare diaphragmatic mobility and thoracic kyphosis between male and female patients with COPD. Methods: Participants underwent anthropometry, spirometry, thoracic kyphosis measurement, and evaluation of diaphragmatic mobility. Results: A total of 34 patients with COPD participated in the study. Diaphragmatic mobility was significantly lower in the group of COPD patients with thoracic hyperkyphosis than in that of those without it $(p=0.002)$. There were no statistically significant differences between the two groups of COPD patients regarding lung function or respiratory muscle strength variables. There was a significant negative correlation between thoracic kyphosis angle and diaphragmatic mobility $(r=-0.47$; $p=0.005)$. In the sample as a whole, there were statistically significant differences between males and females regarding body weight $(p=0.011)$, height $(p<0.001)$, and thoracic kyphosis angle $(p=0.036)$; however, there were no significant differences in diaphragmatic mobility between males and females $(p=0.210)$. Conclusions: Diaphragmatic mobility is lower in COPD patients with thoracic hyperkyphosis than in those without it. There is a negative correlation between thoracic kyphosis angle and diaphragmatic mobility. In comparison with male patients with COPD, female patients with COPD have a significantly increased thoracic kyphosis angle.
\end{abstract}

Keywords: Pulmonary disease, chronic obstructive; Kyphosis; Diaphragm.

\section{INTRODUCTION}

A respiratory disease that is characterized by chronic airflow obstruction, lung hyperinflation, and air trapping, COPD is preventable and treatable. ${ }^{(1)}$ However, the aforementioned pathophysiological factors can lead to a decrease in diaphragmatic mobility among other problems. ${ }^{(2,3)}$

Diaphragmatic mobility has been found to be lower in patients with COPD than in healthy elderly individuals. In addition, air trapping has been shown to be the major factor limiting diaphragmatic mobility in COPD patients. ${ }^{(2)}$ A decrease in diaphragmatic mobility has been found to result in reduced exercise capacity and increased sensation of dyspnea after submaximal exercise. ${ }^{(3)}$

In addition to impaired diaphragmatic function, patients with COPD can present with postural changes such as posterior pelvic tilt, anterior pelvic rotation, and increased thoracic kyphosis when compared with healthy individuals. ${ }^{(4)}$ Other changes in rib cage configuration have been reported in COPD patients, including an increased anteroposterior chest diameter, ${ }^{(5)}$ horizontally oriented ribs, ${ }^{(6)}$ and an increased thoracic curvature, ${ }^{(4)}$ all of which appear to be associated with changes in lung mechanics.

Despite the scarcity of quantitative studies of postural changes in patients with COPD, clinical practice shows that COPD patients have a forward head posture, a decreased cervical lordosis, rounded shoulders, and an increased thoracic kyphosis angle. ${ }^{(7)}$

Although a decrease in diaphragmatic mobility and an increase in thoracic kyphosis are common in patients with COPD, it has yet to be determined whether patients with an increased thoracic kyphosis angle (a determinant of thoracic hyperkyphosis) have decreased diaphragmatic mobility.

The objectives of the present study were as follows: 1) to compare diaphragmatic mobility between COPD patients with and without thoracic hyperkyphosis; 2) to determine the relationship of thoracic kyphosis angle with diaphragmatic mobility and lung function variables in COPD patients; and 3) to compare diaphragmatic

Correspondence to:

Elaine Paulin. Departamento de Fisioterapia, Universidade do Estado de Santa Catarina, Centro de Ciências da Saúde e do Esporte, Rua Pascoal Simone, 358 ,

Coqueiros, CEP 88080-350, Florianópolis, SC, Brasil.

Tel.: 5548 3664-8621. E-mail: elaine.paulin@udesc.br

Financial support: None. 
mobility and thoracic kyphosis between male and female patients with COPD.

\section{METHODS}

\section{Patients and procedures}

This was a quantitative analytical cross-sectional study. A total of 58 patients were recruited from among those being followed at the Pulmonology Outpatient Clinic of the Hospital Universitário Professor Polydoro Ernani de São Thiago, located in the city of Florianópolis, Brazil. The study was approved by the Human Research Ethics Committee of the Universidade do Estado de Santa Catarina, located in the same city, Brazil (CAAE: 08857612.2.0000.0118). All participating patients gave written informed consent, in accordance with Brazilian National Health Council Resolution 466/12.

The study sample intentionally comprised patients who had been diagnosed with COPD in accordance with the Global Initiative for Chronic Obstructive Lung Disease criterion of $\mathrm{FEV}_{1} / \mathrm{FVC}<0.70$ after bronchodilator use. ${ }^{(1)}$ Other inclusion criteria included 1 ) being clinically stable, i.e., no hospitalizations or respiratory attacks in the last month or before testing, 2) requiring no oxygen supplementation, 3) having no associated respiratory, cardiovascular, or musculoskeletal diseases, 4) having participated in no respiratory therapy programs in the six months prior to the study, 5) having recently undergone no spinal or lower limb surgery, and 6) having had no fractures in the last six months.

The exclusion criteria were as follows: experiencing COPD exacerbation during the study period; 2 ) having cardiorespiratory or musculoskeletal complications during the tests; 3 ) being unable to perform any of the required tests (being unable to understand the instructions or being uncooperative); and 4) dropping out during testing.

\section{Anthropometry}

Body weight was measured with a previously calibrated scale (W200/5; Welmy S.A., Sao Paulo, Brazil). Participants stood erect, barefoot and wearing light clothing, with the head in the vertical position, looking straight ahead. Height was measured with a stadiometer, with participants standing barefoot and as erect as possible, with both ankles together. The body mass index (BMI) was calculated by the formula weight/height ${ }^{2}\left(\mathrm{~kg} / \mathrm{m}^{2}\right)$. On the basis of their BMI, participants were stratified into the following categories: underweight ( $\leq 18.5 \mathrm{~kg} / \mathrm{m}^{2}$ ); normal weight (18.5-24.9 kg/m²); overweight (25-29.9 kg/ $\left.\mathrm{m}^{2}\right)$; and obese $\left(\geq 30 \mathrm{~kg} / \mathrm{m}^{2}\right) .{ }^{(8)}$

\section{Lung function}

A previously calibrated portable digital spirometer (EasyOne ${ }^{\circledR}$; ndd Medical Technologies, Zurich, Switzerland) was used in order to assess lung function, in accordance with the methods and criteria recommended by the American Thoracic Society and the European Respiratory Society. ${ }^{(9)}$ The following parameters were measured: FVC; $\mathrm{FEV}_{1}$; and $\mathrm{FEV}_{1} /$ FVC. Participants performed respiratory maneuvers before and 15 min after inhalation of a bronchodilator (albuterol, $400 \mu \mathrm{g}$ ). A minimum of three acceptable maneuvers and two reproducible maneuvers were performed. All spirometric variables were expressed as absolute values and as a percentage of reference values, in accordance with Pereira et al.(10)

\section{Respiratory muscle strength}

A digital manometer (MVD500 ${ }^{\circledR}$; Globalmed, Porto Alegre, Brazil) attached to a mouthpiece with an air outlet of $1 \mathrm{~mm}$ in diameter was used in order to measure respiratory muscle strength. MIP and MEP were measured as indicators of inspiratory and expiratory muscle strength, respectively, in accordance with the Brazilian Thoracic Association guidelines. (11) MIP was measured after a maximal expiratory maneuver (from RV to TLC), whereas MEP was measured after a maximal inspiratory maneuver (from TLC to RV). Participants performed three to five maneuvers in order to obtain three acceptable maneuvers (i.e., without leaks and lasting at least $2 \mathrm{~s}$ ) and at least two reproducible maneuvers. The highest values of three correctly performed maneuvers (the difference among values being $\leq 10 \%$ ) were recorded as MIP and MEP. ${ }^{(12)}$

\section{Thoracic kyphosis angle}

The thoracic kyphosis angle was measured with the flexicurve ruler, which is an $80-\mathrm{cm}$ strip of flexible metal covered in durable plastic (TRIDENT ${ }^{\circledR}$ Indústria de Precisão, Itapuí, Brazil). During thoracic kyphosis angle measurements, participants wore a disposable gown with the opening to the back and were instructed to stand still with their elbows and shoulders extended along the body. Subsequently, the spinous processes of C7 and T12 were identified and marked with a grease pencil. One end of the flexicurve ruler was placed on the $\mathrm{C7}$ spinous process and the ruler was molded to the thoracic kyphosis, the other end of the ruler being placed on the T12 spinous process. The ruler was then transferred to graph paper, onto which the shape was traced. Subsequently, a straight line was drawn connecting $\mathrm{C} 7$ to $\mathrm{T} 12$, being designated Xtotal (the length of the entire thoracic curve, in $\mathrm{cm}$ ). Another straight line was drawn connecting the kyphosis apex to Xtotal, being designated $\mathrm{H}$ (the apex kyphosis height, in $\mathrm{cm}$ ). Yet another straight line was drawn from $\mathrm{T} 12$ to $\mathrm{H}$, being designated Xhalf (half the length of the thoracic curve, in cm; Figure 1). Finally, the flexicurve kyphosis angle was calculated with the use of a third-degree polynomial. ${ }^{(13)}$

In adult patients, thoracic kyphosis angles of $20-50^{\circ}$ were considered normal, whereas, in elderly patients, thoracic kyphosis angles of up to $56^{\circ}$ were considered normal. ${ }^{(14)}$

\section{Diaphragmatic mobility (right hemidiaphragm)}

Diaphragmatic mobility was evaluated by anteroposterior chest $\mathrm{X}$-rays. Initially, a radiopaque ruler 
was placed longitudinally under the right hemithorax in the craniocaudal direction, near the thoracoabdominal junction. Subsequently, anteroposterior chest X-rays were taken with patients lying supine on a fluoroscopy table. Prior to that, patients had been asked to perform two series of ten repetitions of diaphragmatic breathing, $1 \mathrm{~min}$ apart and supervised by a respiratory therapist, in order to become familiar with diaphragmatic breathing for maximal evaluation of diaphragm amplitude during radiographic examination.

After having become familiar with diaphragmatic breathing, patients performed two slow vital capacity maneuvers using a spirometer (Wright/Haloscale Respirometer ${ }^{\circledR}$; Ferraris Medical Ltd., Hertford, England). Slow vital capacity maneuvers were performed from TLC to RV and from RV to TLC. The highest value was recorded for comparison with the value obtained during evaluation of diaphragmatic mobility, in order to determine whether patient respiratory (inspiratory and expiratory) efforts were the same before and during evaluation of diaphragmatic mobility.

The same film was used for all examinations, which were performed during a maximal inspiratory maneuver and a maximal expiratory maneuver. Diaphragmatic mobility was determined by measuring the distance between points at maximum inhalation and exhalation ${ }^{(15)}$ (Figure 2).

For correction of the magnification caused by the divergence of the X-rays, the distance between two

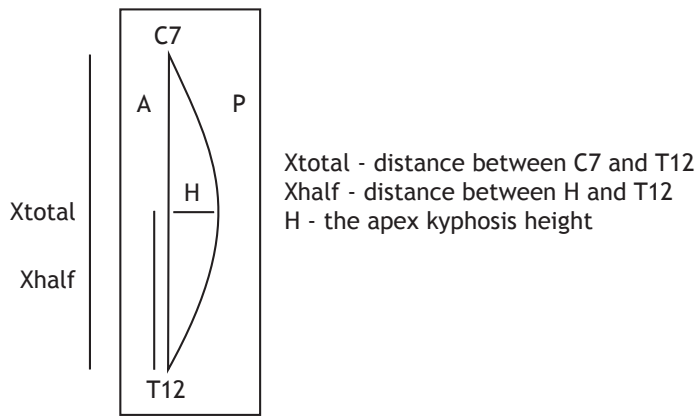

Figure 1. Schematic illustration of thoracic kyphosis measurement with the flexicurve ruler. A: anterior region; and P: posterior region. Source: Teixeira et al. ${ }^{(13)}$ radiopaque ruler graduation marks corresponding to $10 \mathrm{~mm}$ was measured. The corrected diaphragmatic mobility (in $\mathrm{mm}$ ) was obtained by the following formula:

$$
\begin{array}{r}
\text { Corrected mobility }=\quad \frac{\text { measured mobility } \times 10}{\text { measured distance between }} \\
\text { two ruler graduation marks }
\end{array}
$$

\section{Statistical analysis}

A sample size spreadsheet was used in order to calculate sample size. Sample size calculation was based on a pilot study involving 10 COPD patients with thoracic hyperkyphosis and 10 COPD patients without thoracic hyperkyphosis, the difference in diaphragmatic mobility between the two groups of patients being assumed to be $20.29 \mathrm{~mm}$. For a standard deviation of 20.54 (the largest standard deviation), a type I error of 0.05 , and a study power of 0.80 , the required sample size was calculated to be 34 (17 per group). Loss to follow-up was estimated at $10 \%$.

Data were analyzed with the IBM SPSS Statistics software package, version 20.0 for Windows (IBM Corporation, Armonk, NY, USA) and described as mean and standard deviation for all variables. Normality of the data was tested by the Shapiro-Wilk test. The Student's t-test (for parametric data) or the Mann-Whitney test (for nonparametric data) was used in order to compare the parameters between the two groups. Pearson's and Spearman's correlation coefficients were used for parametric and nonparametric data, respectively. The level of significance was set at $5 \%(p<0.05)$.

\section{RESULTS}

A total of 58 patients were initially evaluated. Of those, 24 were excluded from the final analysis: 17 because COPD was not their primary diagnosis and 7 because they did not complete all tests. Of those 7 patients, 3 were excluded because they were unable to perform one or more of the required tests (either because they were unable to understand the instructions or because they were uncooperative) and 4 were excluded because they dropped out during the evaluation period. Therefore, 34 COPD patients were included in the final analysis. Of those, 18 (53\%)
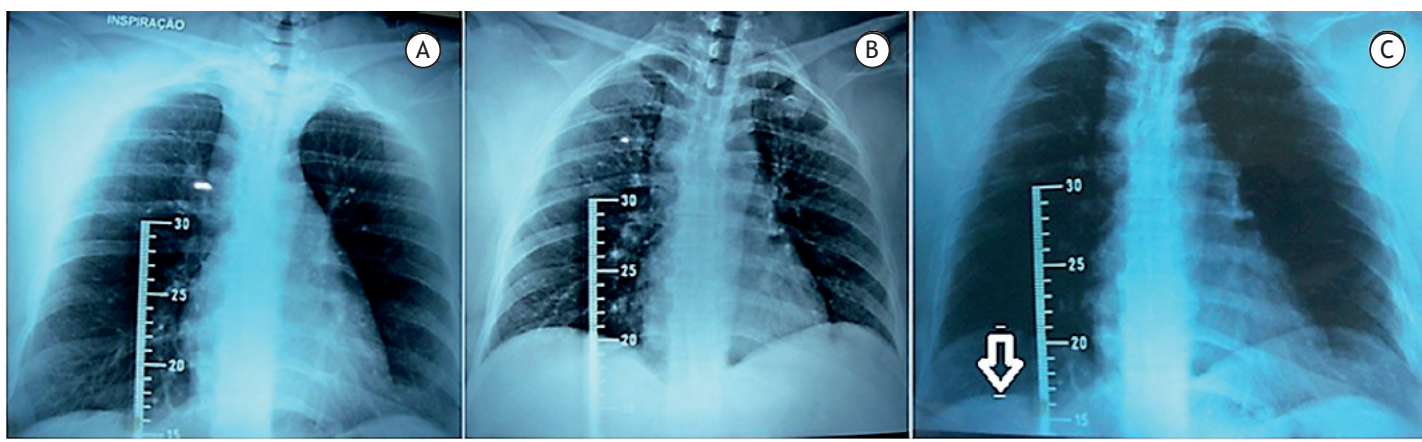

Figure 2. Chest X-rays showing diaphragmatic mobility. In A, chest X-ray taken during a maximal inspiratory maneuver In $B$, chest $X$-ray taken during a maximal expiratory maneuver. In C, superimposition of the two aforementioned images (i.e., the image in $B$ superimposed onto the image in $A$ ), the image of the radiopaque ruler being used as reference. Source: Saltiel et al. ${ }^{(15)}$ 
were male and $16(47 \%)$ were female. The patients were divided into two groups: COPD with thoracic hyperkyphosis $(n=17)$ and COPD without thoracic hyperkyphosis $(n=17)$. The groups were matched for age, weight, height, and BMI.

Table 1 shows the characteristics of the two groups of COPD patients and a comparison of the study variables between the two. There were no statistically significant differences between the two groups regarding lung function or respiratory muscle strength variables.

Diaphragmatic mobility was significantly lower in the group of COPD patients with thoracic hyperkyphosis than in that of those without it $(34.76 \pm 14.18 \mathrm{~mm}$ vs. $53.37 \pm 18.27 \mathrm{~mm}$; $\mathrm{p}=0.002$; Figure 3).

Although the thoracic kyphosis angle correlated negatively with diaphragmatic mobility $(r=-0.47$; $p=0.005$ ), it did not correlate with lung function or respiratory muscle strength variables in the sample as a whole (Table 2).

In the sample as a whole, there were statistically significant differences between males and females regarding body weight, height, and thoracic kyphosis angle. There was no significant difference in diaphragmatic mobility between males and females (Table 3).

\section{DISCUSSION}

In the present study, diaphragmatic mobility was found to be lower in the group of COPD patients with thoracic hyperkyphosis than in that of those without it. It has been shown that a decrease in diaphragmatic mobility is associated with an increased sensation of dyspnea and impaired exercise capacity in patients with COPD. ${ }^{(3)}$ It is also associated with body posture changes in COPD patients. Martinez et al. ${ }^{(16)}$ noted that ineffective diaphragmatic function leads to an apical breathing pattern that is due to a compensatory increase in rib cage and accessory respiratory muscle activity. This can result in increased muscle activity (e.g., increased sternocleidomastoid muscle activity), which results in muscle shortening, decreased muscle flexibility, and head position changes, as well as in shoulder girdle, pelvic girdle, and thoracic spine compensations, ${ }^{(17)}$ all of which can cause thoracic hyperkyphosis.

In the present study, a negative correlation was found between diaphragmatic mobility and thoracic kyphosis, a greater thoracic kyphosis translating to a lower diaphragmatic mobility. This supports the hypothesis that there is an interaction between the two aforementioned variables. However, because of the sample size, it was impossible to determine the influence of those variables on one another, a larger sample being required in order to determine that.

We believe that diaphragmatic impairment plays a role in increasing thoracic kyphosis; however, other COPD-related factors also play a role in that process, including an increased anteroposterior chest diameter, ${ }^{(7)}$ horizontally oriented ribs, ${ }^{(6)}$ and excessive recruitment of accessory muscles. ${ }^{(16)}$

It is extremely important to investigate the relationship among the aforementioned factors because advancedstage COPD and increased thoracic kyphosis can further reduce diaphragmatic mobility and affect lung function, which is reduced in patients with COPD.

According to Loubresse et al., ${ }^{(18)}$ an increased thoracic kyphosis angle can affect lung function. According to Libby et al.,(19) thoracic kyphosis angles greater than $65^{\circ}$ characterize thoracic hyperkyphosis; in the present study, the mean thoracic kyphosis angle was $55.92^{\circ}$. Therefore, given that none of the patients in the present study had severe thoracic kyphosis, lung function results were similar between the groups of COPD patients with and without thoracic hyperkyphosis.

Table 1. Demographic, anthropometric, and functional characteristics of the groups studied $(n=34){ }^{\text {a }}$

\begin{tabular}{|c|c|c|c|}
\hline \multirow[t]{2}{*}{ Variable } & \multicolumn{2}{|c|}{ Group } & \multirow[t]{2}{*}{ p } \\
\hline & $\begin{array}{l}\text { COPD with hyperkyphosis } \\
\qquad(\mathrm{n}=17)\end{array}$ & $\begin{array}{l}\text { COPD without hyperkyphosis } \\
\qquad(\mathrm{n}=17)\end{array}$ & \\
\hline \multicolumn{4}{|c|}{ Demographic and anthropometric data } \\
\hline M/F gender, $n / n$ & $6 / 11$ & $12 / 5$ & - \\
\hline Age, years & $67.6 \pm 6.1$ & $65.9 \pm 7.9$ & 0.489 \\
\hline Body weight, $\mathrm{kg}$ & $71.6 \pm 14.1$ & $75.2 \pm 15.9$ & 0.492 \\
\hline Height, $\mathrm{cm}$ & $164.00 \pm 8.30$ & $167.65 \pm 6.17$ & 0.162 \\
\hline $\mathrm{BMI}, \mathrm{kg} / \mathrm{m}^{2}$ & $26.6 \pm 4.8$ & $26.6 \pm 4.9$ & 0.974 \\
\hline \multicolumn{4}{|l|}{ Lung function } \\
\hline $\mathrm{FEV}_{1} / \mathrm{FVC}, \mathrm{L}$ & $0.54 \pm 0.12$ & $0.59 \pm 0.10$ & 0.168 \\
\hline $\mathrm{FEV}_{1}, \%$ predicted & $46.8 \pm 17.6$ & $56.2 \pm 19.6$ & 0.109 \\
\hline FVC, \% predicted & $66.2 \pm 12.7$ & $72.5 \pm 20.3$ & 0.283 \\
\hline \multicolumn{4}{|c|}{ Respiratory muscle strength } \\
\hline MIP, \% predicted & $77.8 \pm 26.0$ & $67.6 \pm 20.7$ & 0.216 \\
\hline MEP, \% predicted & $116.1 \pm 27.4$ & $107.7 \pm 32.1$ & 0.417 \\
\hline $\mathrm{DM}, \mathrm{mm}$ & $34.8 \pm 14.2$ & $53.4 \pm 18.3$ & $0.002^{*}$ \\
\hline Thoracic kyphosis angle & $65.3 \pm 6.9$ & $46.3 \pm 5.2$ & $<0.001^{*}$ \\
\hline
\end{tabular}

M: male; F: female; BMI: body mass index; and DM: diaphragmatic mobility. aValues expressed as mean \pm SD, except where otherwise indicated. 
There was no significant difference between the groups of COPD patients with and without hyperkyphosis regarding respiratory muscle strength. In addition, no correlation was found between the thoracic kyphosis angle and MIP or MEP, possibly because MIP and MEP

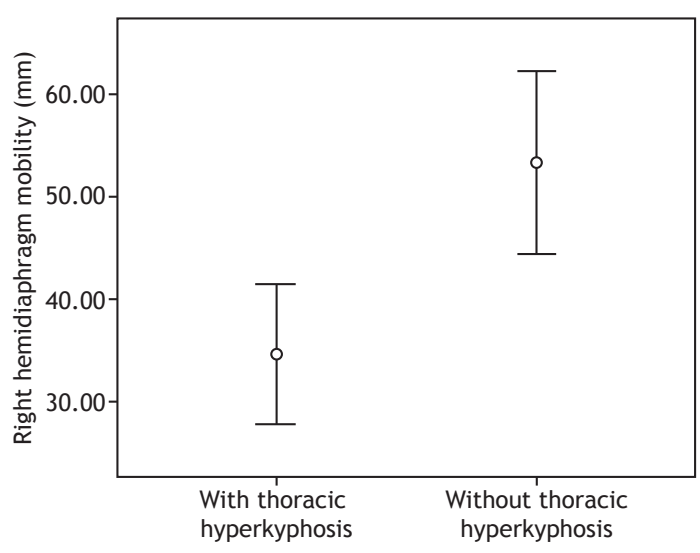

COPD patients

Figure 3. Comparison of diaphragmatic mobility between COPD patients with and without thoracic hyperkyphosis ( $\mathrm{n}$ $=34) \cdot{ }^{*} p=0.002$

Table 2. Relationship of thoracic kyphosis angle with diaphragmatic mobility, lung function, and respiratory muscle strength in the study sample $(n=34)$.

\begin{tabular}{lcc}
\multicolumn{1}{c}{ Variable } & $\begin{array}{c}\text { Correlation } \\
\text { coefficient* }\end{array}$ & p \\
\hline DM & -0.470 & 0.005 \\
FEV $_{1} /$ FVC, L & -0.170 & 0.338 \\
FEV $_{1}, \%$ predicted & -0.223 & 0.206 \\
FVC, \% predicted & -0.142 & 0.423 \\
MIP, \% predicted & 0.204 & 0.247 \\
MEP, \% predicted & 0.086 & 0.629 \\
\hline
\end{tabular}

DM: diaphragmatic mobility. *Pearson's or Spearman's correlation coefficient. are not discriminatory variables. It is possible that mobility is more closely related to parameters such as dynamic and transdiaphragmatic pressures than to maximal static respiratory pressures. Our results are consistent with those of Rennó et al., (20) who studied elderly females with thoracic hyperkyphosis and found no significant correlations between increased thoracic kyphosis and MIP or MEP.

Body weight and height were lower in females than in males, whereas the thoracic kyphosis angle was greater in females than in males. This might be due to postural changes resulting in markedly reduced height because of excessive kyphosis and a forward head posture. ${ }^{(20)}$

Our results are similar to those of a study conducted by Katzman et al.,(21) showing greater thoracic kyphosis in females than in males. Poor postural alignment is associated with spinal extensor muscle weakness and estrogen deficiency. (22) In a study of premenopausal and postmenopausal women, the prevalence of kyphosis was $35 \%$, and kyphosis was found to be associated with age, although only in postmenopausal women. ${ }^{(23)}$ After 40 years of age, the thoracic kyphosis angle might increase more rapidly in females than in males (a mean angle of $43^{\circ}$ in females in the 55- to 60 -year age bracket and of $52^{\circ}$ in females in the 76- to 80 -year age bracket). ${ }^{(24)}$

In our sample as a whole, diaphragmatic mobility was found to be similar between males and females. Our results are consistent with those obtained by Saltiel et al., (15) Grams et al.,(25) Pedrini, (26) and Leal et al., (27) who also found no difference in diaphragmatic mobility between males and females. However Boussuges et al.(28) and Kantarci et al.(29) found differences in diaphragmatic mobility between males and females. This might be due to the sample size, given that the aforementioned studies by Boussuges et al. ${ }^{(28)}$ and Kantarci et al. ${ }^{(29)}$ had a large number of participants (210 and 164 , respectively), whereas

Table 3. Comparison of lung function, respiratory muscle strength, diaphragmatic mobility, and thoracic kyphosis between males and females in the study sample $(n=34){ }^{\text {a }}$

\begin{tabular}{|c|c|c|c|}
\hline \multirow[t]{2}{*}{ Variable } & \multicolumn{2}{|c|}{ Group } & \multirow[t]{2}{*}{$\mathbf{p}$} \\
\hline & $\begin{array}{c}\text { Males } \\
(\mathrm{n}=18)\end{array}$ & $\begin{array}{l}\text { Females } \\
(n=16)\end{array}$ & \\
\hline \multicolumn{4}{|c|}{ Demographic and anthropometric data } \\
\hline Age, years & $67.8 \pm 8.2$ & $65.7 \pm 5.5$ & 0.386 \\
\hline Body weight, $\mathrm{kg}$ & $79.4 \pm 12.5$ & $66.7 \pm 14.9$ & 0.011 \\
\hline Height, $\mathrm{cm}$ & $170.3 \pm 5.9$ & $160.8 \pm 5.5$ & $<0.001$ \\
\hline $\mathrm{BMI}, \mathrm{kg} / \mathrm{m}^{2}$ & $27.3 \pm 4.1$ & $25.8 \pm 5.5$ & 0.353 \\
\hline \multicolumn{4}{|l|}{ Lung function } \\
\hline $\mathrm{FEV}_{1} / \mathrm{FVC}, \mathrm{L}$ & $0.56 \pm 0.13$ & $0.57 \pm 0.10$ & 0.822 \\
\hline $\mathrm{FEV}_{1}, \%$ predicted & $50.0 \pm 20.9$ & $53.0 \pm 17.2$ & 0.666 \\
\hline FVC, \% predicted & $66.5 \pm 17.6$ & $72.5 \pm 16.3$ & 0.317 \\
\hline \multicolumn{4}{|c|}{ Respiratory muscle strength } \\
\hline MIP, \% predicted & $70.6 \pm 25.6$ & $75.1 \pm 22.0$ & 0.596 \\
\hline MEP, \% predicted & $103.7 \pm 26.8$ & $121.1 \pm 30.9$ & 0.088 \\
\hline $\mathrm{DM}, \mathrm{mm}$ & $47.89 \pm 18.62$ & $39.77 \pm 18.35$ & 0.210 \\
\hline Thoracic kyphosis angle & $52.06 \pm 8.91$ & $60.22 \pm 12.68^{*}$ & 0.036 \\
\hline
\end{tabular}

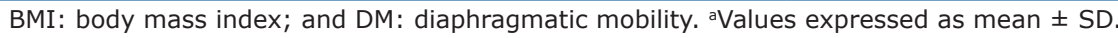


the aforementioned studies by Saltiel et al.,(15) Grams et al.,(25) Pedrini,(26) and Leal et al.(27) had smaller sample sizes (of approximately 40 individuals). It is of note that all of the aforementioned studies involved healthy individuals; we found no studies comparing diaphragmatic mobility between male and female patients with COPD.

One of the strengths of the present study is its methodological rigor in performing the required tests. However, the study has some limitations. Given that neither symptoms nor exercise capacity were evaluated, it was impossible to extrapolate our data on diaphragmatic mobility to the aforementioned outcomes. Given that we had no access to a wholebody plethysmograph, it was impossible to evaluate air trapping and correlate it with diaphragmatic mobility. Further studies are needed in order to investigate the clinical implications of our findings with regard to dyspnea, exercise capacity, and air trapping.

The topic of diaphragmatic mobility in COPD patients with and without thoracic hyperkyphosis is relevant because of the relationship between an increased thoracic kyphosis angle and advancing age. Thoracic hyperkyphosis can further impair diaphragmatic mobility and lung function in COPD patients, whose diaphragmatic mobility and lung function are affected by COPD-related pathophysiological factors.
Because of the cross-sectional nature of the present study, it was impossible to establish a cause-and-effect relationship between an increased thoracic kyphosis angle and a decrease in diaphragmatic mobility. Prospective longitudinal studies are needed in order to demonstrate the real influence of these variables on patients with COPD. Nevertheless, the results of the present study provide important information regarding thoracic kyphosis and diaphragmatic mobility in patients with COPD.

In summary, diaphragmatic mobility is lower in COPD patients with thoracic hyperkyphosis than in those without it; however, lung function and respiratory muscle strength are similar between the two groups of patients. There is a negative relationship between thoracic kyphosis angle and diaphragmatic mobility, and the results of the present study suggest that a greater thoracic kyphosis translates to a lower diaphragmatic mobility. In comparison with male patients with COPD, female patients with COPD have a significantly increased thoracic kyphosis angle.

\section{ACKNOWLEDGMENTS}

We would like to thank Clínica Lâmina Medicina Diagnóstica for their assistance.

\section{REFERENCES}

1. Global Initiative for Chronic Obstructive Lung Disease (GOLD) [homepage on the Internet]. Bethesda: GOLD [cited 2016 Oct 1]. GOLD 2017 Global Strategy for the Diagnosis, Management and Prevention of COPD. Available from: http://goldcopd.org/gold-2017 global-strategy-diagnosis-management-prevention-copd/

2. Dos Santos Yamaguti WP, Paulin E, Shibao S, Chammas MC, Salge JM, Ribeiro M, et al. Air trapping: The major factor limiting diaphragm mobility in chronic obstructive pulmonary disease patients Respirology. 2008;13(1):138-44. https://doi.org/10.1111/j.14401843.2007.01194.x

3. Paulin E, Yamaguti WP, Chammas MC, Shibao S, Stelmach R, Cukier $A$, et al. Influence of diaphragmatic mobility on exercise tolerance and dyspnea in patients with COPD. Respir Med. 2007;101(10):2113 8. https://doi.org/10.1016/j.rmed.2007.05.024

4. Pachioni CA, Ferrante JA, Panissa TS, Ferreira DM, Ramos D Moreira GL, et al. Postural assessment in patients with chronic obstructive pulmonary disease [Article in Portuguese]. Fisioter Pesqui (São Paulo). 2011;18(4):341-5. http://dx.doi.org/10.1590/ S1809-29502011000400008

5. Nicklaus TM, Stowell DW, Christiansen WR, Renzetti AD Jr. The accuracy of the roentgenologic diagnosis of chronic pulmonary emphysema. Am Rev Respir Dis. 1966;93(6):889-99. http://www. atsjournals.org/doi/abs/10.1164/arrd.1966.93.6.889?journalCode=a rrd

6. Soares SM, Carvalho CR. Intolerância ao exercício em pacientes com doença pulmonar obstrutiva crônica. Rev Cienc Med (Campinas). 2009;18(3):143-51. http://periodicos.puc-campinas.edu.br/seer/ index.php/cienciasmedicas/article/view/641

7. Dias CS, Kirkwood RN, Parreira VF, Sampaio RF. Orientation and position of the scapula, head and kyphosis thoracic in male patients with COPD. Can J Resp Ther. 2009;30-34.

8. WHO Consultation on Obesity; World Health Organization. Obesity: preventing and managing the global epidemic: report of a WHO consultation. Geneva: WHO; 2000. http://www.who.int/iris/ handle/10665/42330

9. Miller MR, Hankinson J, Brusasco V, Burgos F, Casaburi R, Coates A Standardisation of spirometry. Eur Respir J. 2005;26(2):319-38. https://doi.org/10.1183/09031936.05.00034805
10. Pereira CA, Sato T, Rodrigues SC. New reference values for forced spirometry in white adults in Brazil. J Bras Pneumol, 2007;33(4):397406. http://dx.doi.org/10.1590/S1806-37132007000400008

11. Sociedade Brasileira de Pneumologia e Tisiologia. Diretrizes para testes de função pulmonar. J Pneumol. 2002;28(Suppl 3):S1-S238. http://www.jornaldepneumologia.com.br/detalhe_suplemento. asp?id=45

12. Neder JA, Andreoni S, Lerário MC, Nery LE. Reference values for lung function tests. II. Maximal respiratory pressures and voluntary ventilation. Braz J Med Biol Res. 1999;32(6):719-27. http://dx.doi org/10.1590/S0100-879X1999000600007

13. Teixeira FA, Carvalho GA. Reliability and validity of thoracic kyphosis measurements using flexicurve method. Rev Bras Fisioter. 2007;11(3):199-204. http://dx.doi.org/10.1590/S141335552007000300005

14. Bandeira FM, Delfino FC, Carvalho GA, Valduga R. Comparison of thoracic kyphosis between sedentary and physically active older adults by the flexicurve method [Article in Portuguese]. Rev Bras Cineantropom Desempenho Hum. 2010;12(5):381-386. http://dx.doi. org/10.5007/1980-0037.2010V12N5P381

15. Saltiel RV, Grams ST, Pedrini A, Paulin E. High reliability of measure of diaphragmatic mobility by radiographic method in healthy individuals. Braz J Phys Ther. 2013;17(2):128-36. http://dx.doi.org/10.1590/ S1413-35552012005000076

16. Martinez FJ, Couser JI, Celli BR. Factors influencing ventilatory muscle recruitment in patients with chronic airflow obstruction Am Rev Respir Dis. 1990;142(2):276-82. https://doi.org/10.1164/ ajrccm/142.2.276

17. Corrêa EC, Bérzin F. Efficacy of physical therapy on cervical muscle activity and on body posture in school-age mouth breathing children. J Pediatr Otorhinolaryngol. 2007;71(10):1527-35. https://doi. org/10.1016/j.ijporl.2007.05.031

18. Loubresse CG, Vialle R, Wolff S. Pathological kyphosis [Article in French]. EMC Rhumatol Orthop. 2005;2(3):294-334. https://doi. org/10.1016/j.emcrho.2004.11.002

19. Libby DM, Briscoe WA, Boyce B, Smith JP. Acute respiratory failure in scoliosis or kyphosis: prolonged survival and treatment. Am J Med. 1982;73(4):532-8. https://doi.org/10.1016/0002-9343(82)90332-1 
20. Rennó AC, Granito RN, Driusso P, Costa D, Oishi J. Correlações entre grau de cifose torácica, função pulmonar e qualidade de vida em mulheres com osteoporose. Rev. Fisioter Univ São Paulo. 2004;11(1):24-31. http://dx.doi.org/10.1590/fpusp.v1111.76775

21. Katzman WB, Wanek L, Shepherd JA. Sellmeyer DE. Age-related hyperkyphosis: its causes, consequences, and management. J Orthop Sports Phys Ther. 2010;40(6);352-60. https://doi.org/10.2519/ jospt.2010.3099

22. Hinman MR. Comparison of thoracic kyphosis and postural stiffness in younger and older women. Spine J. 2004;4(4):413-7. https://doi. org/10.1016/j.spinee.2004.01.002

23. Cutler WB, Friedmann E, Genovese-Stone E. Prevalence of kyphosis in a healthy sample of pre-and postmenopausal women. Am J Phys Med Rehab. 1993;72(4):219-25. http://europepmc.org/abstract/med/8363818

24. Ensrud KE, Black DM, Harris F, Ettinger B, Cummings SR. Correlates of kyphosis in older women. The Fracture Intervention Trial Research Group. J Am Geriatr Soc. 1997;45(6):682-7. https://doi. org/10.1111/j.1532-5415.1997.tb01470.x

25. Grams ST, von Saltiél RV, Mayer AF, Schivinski Cl, de S Nobre LF,
Nóbrega IS, et al. Assessment of the reproducibility of the indirect ultrasound method of measuring diaphragm mobility. Clin Physio Funct Imaging. 2014;34(1):18-25. https://doi.org/10.1111/cpf.12058

26. Pedrini A. Validade e confiabilidade da medida da mobilidade diafragmática pela área radiográfica. [dissertation] Florianópolis: Universidade do Estado de Santa Catarina; 2013

27. Leal BE, Gonçalves MA, Lisboa LG, Linné LMS, Tavares MGS Yamaguti WP, et al. Validity and reliability of fluoroscopy for digital radiography: a new way to evaluate diaphragmatic mobility. BMC Pulm Med. 2017 Apr 17;17(1):62. https://doi.org/10.1186/s12890017-0402-x

28. Boussuges A, Gole Y, Blanc P. Diaphragmatic motion studied by m-mode ultrasonography: methods, reproducibility, and norma values. Chest. 2009;135(2):391-400. https://doi.org/10.1378/ chest.08-1541

29. Kantarci F, Mihmanli I, DemireL MK, Harmanci K, Akman C, Aydogan $F$, et al. Normal diaphragmatic motion and the effects of body composition: determination with M-mode sonography. J Ultrasound Med. 2004;23(2):255-60. https://doi.org/10.7863/jum.2004.23.2.255 